\title{
Chewing Gum Degradation as an Environmental Awakening Tool
} \author{
Leila Y Visconte ${ }^{1}$ and Fernando Gomes de Souza Jr ${ }^{1,3 *}$ \\ ${ }^{1}$ Instituto de Macromoléculas, Brasil \\ ${ }^{2}$ Escola de Química, Brasil \\ ${ }^{3}$ Programa de Engenharia Civil, Brasil \\ *Corresponding author: Fernando Gomes de Souza, Programa de Engenharia Civil, Brasil
}

Fabíola da Silveira Maranhão ${ }^{1}$, Daniela Marques ${ }^{1}$, Thuanny Moraes de Almeida ${ }^{1}$, Priscilla Braga Antunes Bedor ${ }^{1,2}$,

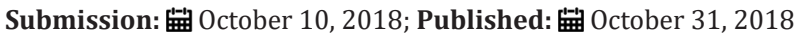

\begin{abstract}
Many of the environmental impacts are caused by improper waste disposal, including those which are quickly consumed, such as chewing gum. The lack of information regarding the environmental problems caused by these materials is one of the issues which can be solved by Environmental Education. This pathway can make individuals aware of their responsibilities. In this sense, the present work aims to walk young students through several physical analysis which prove the degradation resistance of the chewing gum before and after undergoing the chewing process. Materials were studied along six months. During this period, a group of students followed the experiment, and they were able to conclude that chewing gun does not degrade quickly, drawing their attention to the Environmental cause.
\end{abstract}

Keywords: Environmental education; Chewing gum; SBR; Degradation

Abbreviations: CAM0: Chewed Sugar Sample in the First Day; CAM1: Chewed Sugar Sample after One Month; CAM6: Chewed Sugar Sample after Six Months; CCA0: Control Sample with Sugar in the First Day; CCA1: Control Sample with Sugar after One Month; CCA6: Control Sample with Sugar after Six Months; SAM0: Chewed Sugarless Sample in the First Day; SAM1: Chewed Sugarless Sample after One Month; SAM6: Chewed Sugarless Sample after Six Months; CSA0: Control Chewed Sugarless Sample in the First Day; CSA1: Control Chewed Sugarless Sample after One Month; CSA6: Control Chewed Sugarless Sample after Six Months; TGA: Thermogravimetric Analyses; SEM: Scanning Electron Microscopy; FTIR: Fourier-Transform Infrared Spectroscopy

\section{Introduction}

Twenty-five years after Agenda 21 from United Nations Conference on Environment and Development be held in Rio de Janeiro, most of the people do not understand the importance of environmental preservation, producing by consequence, environmental problems mainly due to the inappropriate disposal of waste and tailings. Among discarded waste, petrochemical artifacts possess a remarkable relevance, mainly the plastics and elastomers. The latter is mainly composed by tires, shoes and chewing gum. These artifacts are obtained from an amorphous polymer, derived from styrene butadiene rubber (SBR) [1-4]. During their fabrication, these materials pass through a vulcanization process, which imparts crosslinks among the polymer chains. This vulcanization process increases the mechanical resistance of these materials. Unfortunately, this process also decreases the biodegradation of these materials [5-8]. In turn, the SBR food grade rubber used for the production of chewing gum is widely used because of its low cost and ease of processing. It is estimated that the consumption per person of chewing gum in the USA is between 160-180 units per year [9]. Brazilian Government data from 2017 showed that Brazil posses about 51 million young people. Taking into account that each young person consumes 160 units of chewing gum per year, the disposal of these artifacts can be estimated around 8 million units per year. After chewing, the chewing gum presents a sticky character, which causes some discomfort when discarded due to its adhesiveness to surfaces [10-12]. Thus, from an Ecofriendly point of view, the recovery of this material is increasingly essential. Beyond that, the Environmental Education must always be used as a tool to aware people about the proper disposal of their waste and their anthropogenic impacts on Earth. Therefore, the objective of this work is to report our efforts leading a new generation of Brazilians to encourage the preservation of Nature. These educational activities involved the contemplation of the environment and its multiple components in a context that refers to the sustainable use of the resources that surround us. Besides that, this work contemplated the initiation of these young people to the scientific activities, the basis for a world based on equality, which will allow the sustainable development of a new generation free from the vices of the former ones.

\section{Methods}

For the evaluation of the SBR chewing gum degradation after consumption, 18 chewing gums with sugar, 18 chewing gums 
without sugar and 4 chewing guns samples denominated controls with and without sugar were separated. For the exposition to the environment of the chewing gum, it was necessary to count on the help of volunteers, young Ph.D. students of the Federal University of Rio de Janeiro. These 18 students chewed the gums for 10 minutes. After this, these chewing gums samples were kept in Petri dishes by six months. These students were called monthly to follow the characterization experiments. Each time, three chewed samples and one control, were analyzed by Thermogravimetric Analysis (TGA), Infrared Spectroscopy with Fourier Transform (FTIR) and Scanning Electron Microscopy (SEM), the optical micrographs of the samples were also recorded every month of exposure. Aiming these characterizations, Fourier transform infrared spectroscopy using attenuated total reflectance (FTIR-ATR) analyses were performed in a Perkin-Elmer 1720X Fourier transform spectrometer. The FTIR spectra were obtained using ATR (diamond crystal) in an inert atmosphere, with a resolution of $4 \mathrm{~cm}^{-1}$ in the range 4000 $675 \mathrm{~cm}^{-1}$. Stored results were averages of 124 scans. Simultaneous Thermal Analysis (STA) was performed using a PerkinElmer STA 6000. Measurements were carried out under nitrogen at a heating rate of $20^{\circ} \mathrm{C} / \mathrm{min}$ up to $700{ }^{\circ} \mathrm{C}$ with a gas flow rate of $20 \mathrm{~mL} / \mathrm{min}$.
Scanning electron microscopy (SEM) experiments were performed with a JEOL JSM-5610 LV microscope, using acceleration voltage of $15 \mathrm{kV}$. Samples were coated with gold to study the morphology of the prepared materials.

\section{Results}

The analysis of the mass loss of the samples was performed during the months of the experiment, and the results are shown in Table 1. From the results, it was possible to conclude that all the samples kept the same mass along the experimental time. The absence of mass variation is substantial evidence that the tested materials are not readily degradable.

Table 1: Mass of the tested samples along experimental time.

\begin{tabular}{|c|c|c|c|c|}
\hline Time (month) & CSA (wt\%) & CCA (wt\%) & $\begin{array}{c}\text { SAM } \\
\text { (wt\%) }\end{array}$ & CAM (wt\%) \\
\hline 1 & $100.0 \pm 0.7$ & $100.0 \pm 2.3$ & $100.0 \pm 3.0$ & $100.0 \pm 5.2$ \\
\hline 3 & $96.1 \pm 1.3$ & $98.4 \pm 4.0$ & $95.8 \pm 4.5$ & $99.1 \pm 5.6$ \\
\hline 6 & $92.7 \pm 2.1$ & $97.5 \pm 6.4$ & $95.4 \pm 3.9$ & $99.0 \pm 6.6$ \\
\hline
\end{tabular}

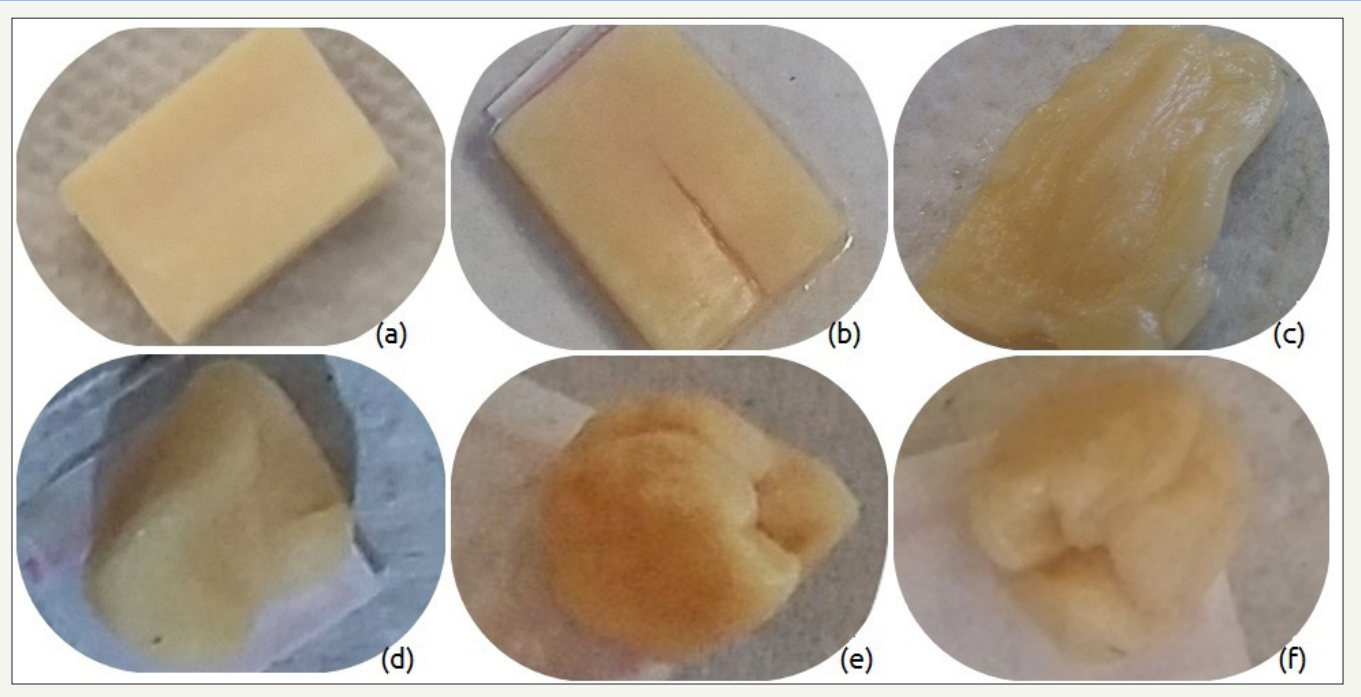

Figure 1: Samples (a)CSA0, (b)CSA1, (c)CSA6, (d)SAM0, (e)SAM1, (f)SAM6.

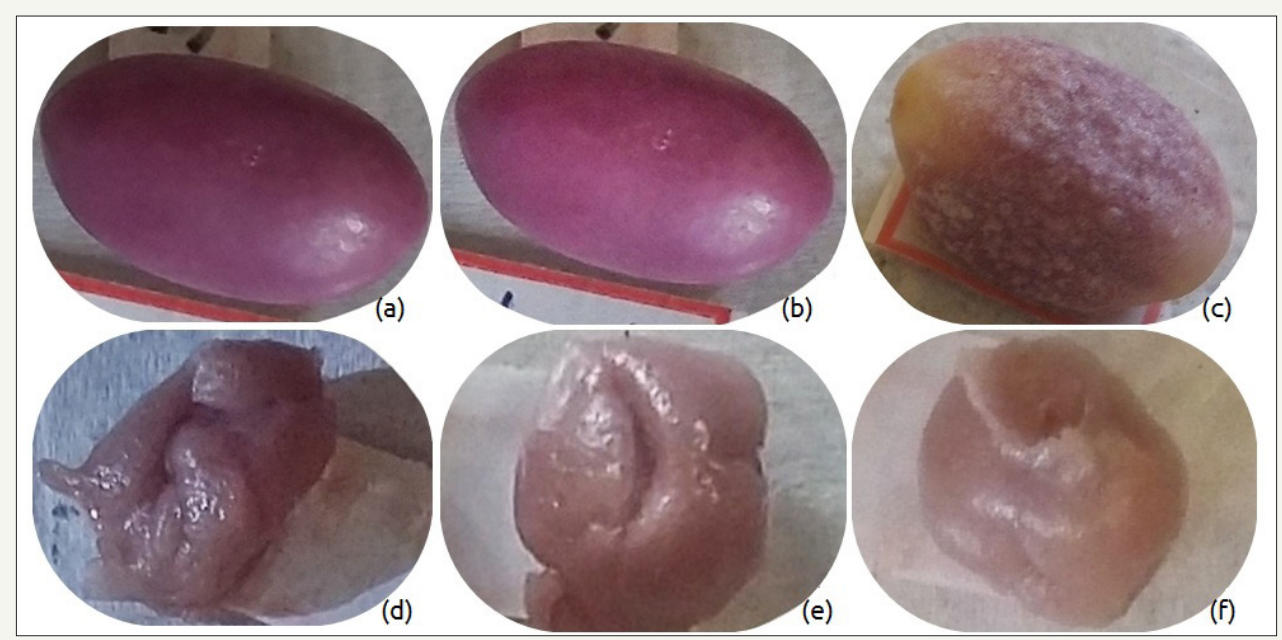

Figure 2: Samples (a)CCA0, (b)CCA1, (c)CCA6, (d)CAM0, (e)CAM1, (f)CAM6. 


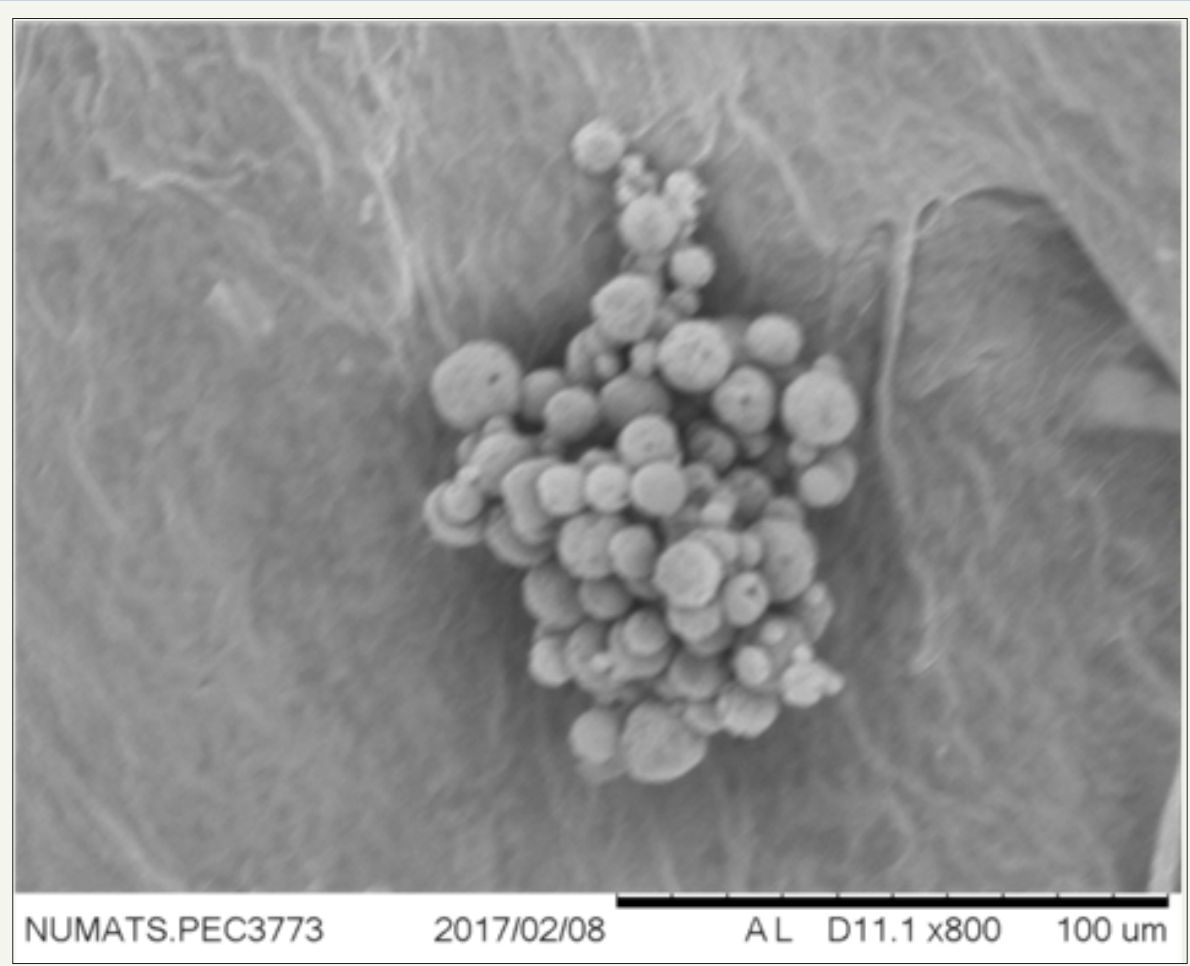

Figure 3: SEM of the CCA sample after six months.

Figure $1 \& 2$ shown some the pictures of the samples taken during the six months of the experiment. The obtained results allowed inferring that mainly samples kept the same colors indicating the lack of degradation. Among tested samples, only the CCA presented in Figure 2 shown decoloration possibly due to the proliferation of bacteria able to degrade sugars. This assumption is proved by the SEM analysis, which shows the proliferation of bacterias only on the surface of the CCA sample, as one can see in Figure 3. The other samples did not present these biostructures of the Staphylococci bacteria on their surface.

TGA results also did not show changes among the samples during the experimental time. The samples presented only the characteristic weight losses of the SBR. These results are in agreement with the FTIR ones. The FTIR spectra of the samples were also performed, and the primary results were quite similar for all of the samples. Specifically, samples presented characteristic FTIR bands of SBR samples. Among them, the one at $3450 \mathrm{~cm}^{-1}$ characteristic of the $\mathrm{OH}$ group; the ones centered at 2919 and $2848 \mathrm{~cm}^{-1}$, which are attributed to the $\mathrm{CH}$ bonds of the styrene aromatic rings. The band at $1456 \mathrm{~cm}^{-1}$ was attributed to the stretching vibration of $\mathrm{CH}_{2}$ and $\mathrm{CH}_{3}$, and the ones centered at 1013 and $666 \mathrm{~cm}^{-1}$, to 1,4-trans-butadiene and 1,4-cis-butadiene, respectively [13].

Thus, experimental results allowed inferring that SBR did not suffer degradation during the six months experiments performed. Despite the high level of formation of the students involved in these experiments, this conclusion was disappointing to a significant part of them, since almost $62 \%$ of the 18 participants believed in the partial degradation of the chewing gum. Therefore, this experiment reached its primary objective, which awakened the environmental awareness of the participants and we hope these young scientists will lead their future research aiming a better world to every one of us.

\section{Conclusion}

From the performed tests, the participants can conclude about the presence of the styrene-butadiene copolymer in the chewing gum. Also, they concluded that these materials, when exposed to the controlled conditions of a chemistry lab environment do not present degradation of the chewing gum. The small degradation observed was just from the sugars and syrups contained in the control samples. Besides helping the students understanding several physical and Environmental concepts, this study also awakens their environmental awareness, and we believe these young scientists will lead their future research aiming a better world able to protect and preserve Environment.

\section{References}

1. Aboelkheir M, Siqueira CYS, Souza FG, Toledo Filho RD (2018) Influence of styrene-butadiene co-polymer on the hydration kinetics of SBRmodified well cement slurries. Macromol Symp 380: 1800131.

2. Khan F, Koo JH, Monk D, Eisbrenner E (2008) Characterization of shear deformation and strain recovery behavior in shape memory polymers. Polym Test 27(4): 498-503.

3. Kundu SP, Chakraborty S, Majumder SB, Adhikari B (2018) Effectiveness of the mild alkali and dilute polymer modification in controlling the durability of jute fibre in alkaline cement medium. Constr Build Mater 174: $330-342$.

4. Tatarua JD, Popaa M (2011) Magnetic microparticles based on natural polymers. International Journal of Pharmaceutics 404(1-2): 83-93. 
5. Chmielewski AG, Haji-Saeid M, Ahmed S (2005) Progress in radiation processing of polymers Nuclear Instruments and Methods in Physics Research Section B: Beam Interactions with Materials and Atoms 236(14): 44-54.

6. Souza FG, Almeida M, Soares BG, Pinto JC (2007) Preparation of a semiconductive thermoplastic elastomer vulcanizate based on EVA and NBR blends with polyaniline. Polym Test 26(5): 692-697.

7. Oliveira MA de S, Cassu SN, Mello SAC de, Dutra ICN (2016) Influência do método de vulcanização nas propriedades mecânicas e na densidade de ligações cruzadas da borracha natural. Polímeros 26: 43-48.

8. Aboelkheir MG, Visconte LY, Oliveira GE (2019) The biodegradative effect of Tenebrio molitor Linnaeus larvae on vulcanized SBR and tire crumb. Sci Total Environ 649: 1075-1082.
9. Konar N, Palabiyik I, Toker OS, Sagdic O (2016) Chewing gum: Production, quality parameters and opportunities for delivering bioactive compounds. Trends Food Sci Technol 55: 29-38.

10. Sanchez C, Nigen M, Mejia Tamayo V (2018) Acacia gum: History of the future. Food Hydrocoll 78: 140-160.

11. Samiei N, Olyaie E, Saberi S, Zolfaghari ME (2018) Development of a gum base formulation for nystatin; a new drug delivery approach for treatment of oral candidiasis. J Drug Deliv Sci Technol 48: 59-65.

12. Gowthamarajan K, Kumar GKP, Gaikwad NB, Suresh B (2011) Preliminary study of Anacardium occidentale gum as binder in formulation of paracetamol tablets. Carbohydr Polym 83(2): 506-511.

13. Gp K (2017) Synthesis, characterization and flocculation characteristics of polysaccharide graft copolymers. Res Dev Mater Sci 1(4).

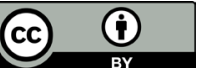

Creative Commons Attribution 4.0 International License

For possible submissions Click Here

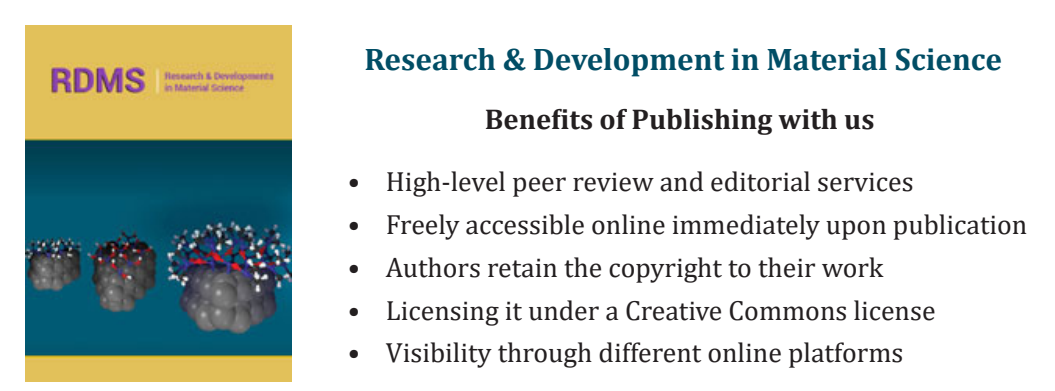

